\title{
Findings from two large randomized controlled trials on renal replacement therapy in acute kidney injury
}

\author{
Teruhiko Yoshida', Yohei Komaru', Ryo Matsuura', Yoshihisa Miyamoto², Kohei Yoshimoto², Eisei Noiri', \\ Masaomi Nangaku', Naoki Yahagi ${ }^{2}$ and Kent Doi ${ }^{2 *}$
}

\begin{abstract}
Many issues regarding the management of renal replacement therapy (RRT) in acute kidney injury (AKI) including timing of initiation, selection of RRT modality, and optimal dosing remain to be resolved. Two major randomized controlled trials, the Veterans Affairs/National Institutes of Health (VA/NIH) Acute Renal Failure Trial Network (ATN) and the Randomized Evaluation of Normal versus Augmented Level (RENAL) studies, which were elaborately designed to evaluate the benefit for delivering RRT of higher intensity in critically ill patients, were characterized by their sophisticated design, large sample sizes, and comprehensive data collection. Although no beneficial effect of higher intensity RRT was demonstrated by these studies, many ancillary studies conducted subanalyses which provided additional findings on other important clinical questions that remained unsolved. This review aims to overview the useful information obtained by the VA/NIH ATN and the RENAL studies to gain useful insights for optimal RRT in AKl.
\end{abstract}

Keywords: Acute kidney injury, Renal replacement therapy, Subanalysis, The Veterans Affairs/National Institutes of Health (VA/NIH), Acute Renal Failure Trial Network (ATN) study, The Randomized Evaluation of Normal versus Augmented Level (RENAL) study

\section{Background}

The incidence of acute kidney injury (AKI) in the intensive care unit (ICU) is unacceptably high, affecting approximately two thirds of the patients $[1,2]$. Among those with severe AKI, 50-70 \% eventually receive renal replacement therapy (RRT) [3]. Furthermore, AKI in the ICU is associated with higher mortality, particularly in patients receiving RRT with 50-60\% mortality [3]. Even after surviving hospitalization with AKI, dialysis dependence rate in these patients following discharge is between 5 and $20 \%[3,4]$. In addition to these poor outcomes, many fundamental issues regarding the management of RRT in AKI need to be resolved to improve its prognosis.

The Veterans Affairs/National Institutes of Health (VA/NIH) Acute Renal Failure Trial Network (ATN) [5] and the Randomized Evaluation of Normal versus

\footnotetext{
* Correspondence: kdoi-tky@umin.ac.jp

${ }^{2}$ Department of Emergency and Critical Care Medicine, The University of

Tokyo, 7-3-1 HongoBunkyo, Tokyo 113-8655, Japan

Full list of author information is available at the end of the article
}

Augmented Level (RENAL) studies [6] were two major randomized controlled trials (RCTs) that evaluated the benefit of higher-intensity RRT. Although no beneficial effect because of higher RRT intensity was demonstrated by these studies, several subanalysis studies provided useful information on the management of RRT in AKI as these studies enrolled sufficient number of patients and obtained comprehensive and detailed clinical data.

\section{Review}

Unanswered questions in RRT for treatment of AKI

The Kidney Disease: Improving Global Outcomes (KDIGO) Clinical Practice Guideline for Acute Kidney Injury [7] contains a list of the unanswered questions regarding RRT management for the treatment of AKI with research recommendations in Section 5 (Table 1). In addition to these issues, several topics including mortality prediction, optimal drug prescription and nutritional support, and long-term outcomes, such as renal recovery and quality of life, in dialysis-requiring AKI remain unresolved. 
Table 1 Topics of RRT in AKI described in the KDIGO guidelines

Timing of RRT in AKI

Criteria for stopping RRT in AK

Anticoagulation

Vascular access for RRT in AKI

Dialyzer membranes for RRT in AKI

Modality of RRT for patients with AKI

Buffer solutions for RRT in patients with AKI

Dose of RRT in AKI

$R R T$ renal replacement therapy, AKI acute kidney injury, KDIGO Kidney Disease: Improving Global Outcome

Although no RCTs have been conducted to directly address these questions, the subanalysis of large clinical trials may provide useful information (Table 2).

\section{Dose of RRT in AKI}

Dose of RRT in AKI has been investigated by two major RCTs, the VA/NIH ATN and the RENAL studies.
KDIGO guideline recommends delivering a Kt/V of 3.9 per week for intermittent RRT or an effluent volume of $20-25 \mathrm{ml} / \mathrm{kg} / \mathrm{h}$ for continuous renal replacement therapy (CRRT) in AKI based on the findings of these two trials. The VA/NIH ATN study was a multicenter, prospective, randomized, parallel group trial of two strategies for RRT in critically ill patients with AKI conducted at 27 VA and university-affiliated medical centers; 1124 critically ill patients with AKI and failure of at least one non-renal organ or sepsis were randomly assigned to receive either intensive or less intensive RRT. The primary endpoint was death from any cause by day 60. In the group receiving the intensive/less intensive therapy strategy, intermittent hemodialysis (IHD) and sustained low-efficiency dialysis (SLED) were provided three to six times per week, and continuous hemodiafiltration was prescribed to provide a total effluent flow rate of 35 or $20 \mathrm{ml} / \mathrm{kg} / \mathrm{h}$. The results showed no significant differences in the rate of death from any cause by day 60 , the duration of RRT, the rate of recovery of

Table 2 Subanalysis of the VA/NIH ATN and the RENAL studies

\begin{tabular}{|c|c|c|c|c|}
\hline Topics & & Author (year) & Ref & Main result \\
\hline \multirow[t]{4}{*}{ Dose } & VA/NIH ATN & Palevsky (2008) & {$[5]$} & No difference in 60-day mortality between the intensive and less intensive groups \\
\hline & RENAL & Bellomo (2009) & {$[6]$} & No difference in 90-day mortality between the higher and lower intensity groups \\
\hline & RENAL & Bellomo (2013) & {$[8]$} & $\begin{array}{l}\text { No difference in base excess correction between the higher and lower intensity } \\
\text { groups. The higher intensity group had a greater increase in MAP and a decrease } \\
\text { in norepinephrine dose. }\end{array}$ \\
\hline & VA/NIH ATN & Overberger (2007) & [9] & $\begin{array}{l}\text { Intermittent hemodialysis and CRRT were the most commonly used RRT modalities } \\
\text { in the USA. Most practitioners neither dosed CRRT based on patient weight nor } \\
\text { routinely assessed the delivered dosage of hemodialysis. }\end{array}$ \\
\hline Timing & RENAL & Jun (2014) & {$[16]$} & $\begin{array}{l}\text { Earlier commencement of continuous RRT relative to RIFLE-I AKI onset was not } \\
\text { significantly associated with improved mortality. }\end{array}$ \\
\hline Risk prediction & VA/NIH ATN & Demirjian (2011) & {$[20]$} & $\begin{array}{l}21 \text { independent predictors of } 60 \text {-day mortality were identified. The new risk model } \\
\text { outperformed existing generic and disease-specific scoring systems in predicting } \\
60 \text {-day mortality. }\end{array}$ \\
\hline \multirow[t]{2}{*}{ Drug } & RENAL & Wang (2014) & [23] & $\begin{array}{l}\text { The use of ACE-I during the study was not common and, after adjustment for } \\
\text { time-dependent covariates, was not significantly associated with reductions in mortality. }\end{array}$ \\
\hline & RENAL & Roberts (2015) & {$[25]$} & $\begin{array}{l}\text { CRRT dose did not influence overall (systemic) antibiotic clearance, volume of } \\
\text { distribution, or half-life. The proportion of systemic clearance due to CRRT varied widely. }\end{array}$ \\
\hline \multirow[t]{2}{*}{ Nutrition } & RENAL & Bellomo (2014) & {$[36]$} & $\begin{array}{l}\text { Mean DPI was markedly below current recommendations. On multivariate } \\
\text { analysis, a lower DPI was not associated with increased 90-day mortality. }\end{array}$ \\
\hline & RENAL & Bellomo (2014) & {$[32]$} & $\begin{array}{l}\text { Mean } \mathrm{DCl} \text { during treatment in ICU was low. On multivariable analysis, DCI was } \\
\text { not associated with a significant difference in 90-day mortality. }\end{array}$ \\
\hline Renal recovery & VA/NIH ATN & Srisawat (2011) & {$[41]$} & $\begin{array}{l}\text { For predicting renal recovery, decreasing urine biomarkers in the first } 14 \text { days was } \\
\text { associated with greater odds of renal recovery. }\end{array}$ \\
\hline \multirow[t]{3}{*}{ Quality of life } & VA/NIH ATN & Johansen (2010) & [43] & $\begin{array}{l}\text { Health utility was low in this cohort of patients after AKI, and intensity of dialysis } \\
\text { did not affect subsequent health utility. }\end{array}$ \\
\hline & VA/NIH ATN & Joyce (2012) & {$[44]$} & $\begin{array}{l}\text { HRQOL was an independent predictor of mortality among survivors of AKI after } \\
\text { adjusting for clinical risk variables. }\end{array}$ \\
\hline & RENAL & Wang (2015) & {$[45]$} & $\begin{array}{l}\text { Survivors of severe AKI in the study had lower physical and mental components } \\
\text { of HRQOL compared with the general population, even after adjustment for } \\
\text { reduced renal function. }\end{array}$ \\
\hline
\end{tabular}

$A C E-I$ angiotensin-converting enzyme inhibitor, $A K I$ acute renal failure, $A T N$ Acute Renal Failure Trial, CRRT continuous renal replacement therapy, $D C I$ delivery of caloric intake, DPI daily protein intake, HRQOL Health-related quality of life, MAP mean arterial pressure, ICU intensive care unit, RENAL Randomized Evaluation of Normal versus Augmented Level, RIFLE-I Risk, Injury, Failure, Loss, End-stage kidney disease (injury), VA/NIH The Veterans Affairs/National Institutes of Health 
kidney function, or non-renal organ failure between the two groups [5].

The RENAL study was a prospective, randomized, parallel group trial designed to assess CRRT at two levels of intensity in critically ill patients with AKI. Eligible 1508 patients were randomly assigned to two groups based on delivery of CRRT with an effluent flow of $40 \mathrm{ml} / \mathrm{kg} / \mathrm{h}$ (higher intensity) or $25 \mathrm{ml} / \mathrm{kg} / \mathrm{h}$ (lower intensity). At 90 days after randomization, 322 deaths occurred in the higher intensity group, whereas 332 deaths were recorded in the lower intensity group; the difference between the two groups was not statistically significant [6].

Although these two RCTs could not prove the benefit of intensive RRT in terms of mortality and renal recovery, other non-primary outcomes including the need for vasopressor drugs, time on mechanical ventilation, or length of ICU and hospital stay were also evaluated. Bellomo and colleagues conducted a nested cohort study of 115 patients from two tertiary ICUs within the RENAL study to compare key aspects of acidosis, mean arterial pressure (MAP), and vasopressor therapy in patients treated with two different CRRT doses. They showed that lower and higher intensity CRRT had similar acid-base effects in patients with acidosis. However, higher intensity CRRT was associated with greater improvements in MAP and vasopressor requirements [8]. A potential mechanism could be a more efficient removal of biologic mediators responsible for hypotension and/or vasodilatation by higher intensity CRRT, which should be validated by future studies.

Most trials studying CRRT dose used the amount of effluent volume normalized by the patient weight. Overberger and colleagues pointed out that only $17.9 \%$ of practitioners reported dosing CRRT according to patient weight and that $78.9 \%$ of practitioners did not routinely assess the delivered hemodialysis dose based on the survey results from study sites of the VA/NIH ATN [9]. Due to daily changes in patient weight in the ICU, CRRT dose could not guaranteed to be equally prescribed throughout the study period when the body weight before the onset of acute illness (VA/NIH ATN study) or at the time of randomization (RENAL study) was used for prescription. Differences between the prescribed and delivered CRRT doses may have had some impact on the outcomes of both clinical trials. Claure-Del Granado and colleagues reported that prescribed clearance overestimated the actual delivered clearance by $23.8 \%$ in 52 AKI patients treated by continuous hemodiafiltration [10]. Future trials need to more clearly determine the dosing parameters and recognize the frequent discrepancy between the prescribed and delivered doses of RRT.

\section{Timing of RRT in AKI}

The time to start RRT is one of the top research priorities and a fundamental clinical question facing nephrologists and intensivists in most cases of severe AKI [11]. While there is still no agreement on the timing of RRT initiation, it is widely accepted that patients with severe hyperkalemia, severe acidosis, diuretic-resistant pulmonary edema, and uremic complications should be dialyzed immediately. Clinicians tend to delay RRT when they suspect that patients may recover on their own and due to concern of risks associated with RRT, including hypotension, arrhythmia, membrane bio-incompatibility, and complications from vascular access and anticoagulant administration. The KDIGO guideline recommended determining reproducible criteria to inform decision to start RRT in AKI patients by future research [7].

There are several observational study results showing positive results with early RRT commencement. One prospective, multicenter, observational cohort study analyzed dialysis initiation in 243 AKI patients. Initiation of RRT at higher blood urea nitrogen (BUN, $>76 \mathrm{mg} / \mathrm{dl})$ was associated with an increased risk of death (relative risk (RR), 1.85; 95 \% confidence interval (CI), 1.16-2.96) after adjustment for clinical background and severity of illness [12]. In another prospective, multicenter observational study with a bigger sample size of 1238 ICU patients with severe AKI, investigators assessed the relationship between patient outcomes and the time to start RRT relative to ICU admission. After adjustment, late RRT (defined by initiation 5 days after ICU admission) was associated with an increase in the odds of death (odds ratio (OR), 2.20; $95 \%$ CI, 1.44-3.37) [13].

A meta-analysis which included data from four RCTs, 1 quasi-RCT, and 18 observational studies suggested a potential advantage of early CRRT commencement, reporting a non-significant point estimate of $36 \%$ mortality risk reduction (RR, 0.61; $95 \% \mathrm{CI}, 0.40-1.05)$ from RCT data [14]. The RCT with the highest quality score in this meta-analysis randomized 106 critically ill patients with AKI to early $(n=70)$ vs. late CRRT initiation $(n=36)$. The early initiation group started RRT within $12 \mathrm{~h}$ of oliguria $(30 \mathrm{ml} / \mathrm{h}$ for $6 \mathrm{~h}$, not responding to diuretics or hemodynamic optimization) or creatinine clearance of $<20 \mathrm{ml} / \mathrm{min}$. The late-initiation group started RRT when classic indications were met. The study did not find differences in ICU or hospital mortality or in renal recovery among survivors; however, their sample size might be too small to allow for definitive conclusions [15].

Jun and colleagues conducted a nested observational cohort study using data from the RENAL study [16]. Earlier commencement of CRRT relative to Risk, Injury, Failure, Loss, End-stage kidney disease-injury (RIFLE-I) AKI onset was not significantly associated with improved mortality; however, non-significant graded increases in the risk of death with progressively delayed CRRT were observed. The study also found a significant association of mortality with BUN levels at the commencement of RRT. The 
results of these previous clinical studies raise questions regarding the standard criteria used to evaluate early versus late RRT commencement. The ideal criteria might not be BUN, time from ICU admission, or AKI onset used in previous observational studies investigating CRRT efficacy. Additional future studies with larger sample sizes and randomization using elaborately designed criteria, potentially with new biomarker levels or systemic severity scores, will address these potential variables.

\section{Risk prediction in AKI}

As widely recognized, the short-term prognosis of AKI patients in the ICU is very poor. Risk assessment and mortality prediction are important for developing new therapeutic interventions against AKI. The application of systemic severity scores for AKI patients has been problematic due to poor discrimination and suboptimal calibration [17, 18]. Chertow and colleagues developed models with the data from the Program to Improve Care in Acute Renal Disease (PICARD) cohort, a registry of critically ill patients with acute renal failure in the ICUs of five academic medical centers in the United States over a 31-month period $(n=618)$ [18]. They demonstrated marginally superior performance characteristics compared with other prediction models of Sepsis-related Organ Failure Assessment (SOFA) or Cleveland Clinic Foundation (CCF) scores, which reportedly could predict the survival of patients with renal failure [19]. The SOFA score was the best performer among all generic severity scores, whereas the CCF score was the best performer among all disease-specific severity scores [18].

Demirjian and colleagues analyzed the data from 1122 subjects enrolled in the VA/NIH ATN study to develop an AKI-specific predictive model for a 60-day mortality. The logistic regression model exhibited good discrimination, with an area under the receiver operating characteristics curve (AUC-ROC) of 0.85 (95\% CI, 0.83-0.88), and a derived integer risk score yielded an AUC-ROC of 0.80 (95\% CI, 0.77-0.83) [20]. The model can be used for risk evaluation and to potentially stratify prospective subjects in clinical AKI trials after further validation of the model in other cohorts.

\section{Optimal drug prescription in AKI}

Although the renoprotective effect of angiotensinconverting enzyme inhibitors (ACE-I) or angiotensin receptor blockers (ARB) in chronic kidney disease (CKD) is well recognized for reducing proteinuria and slowing progression of renal dysfunction, the role of ACE-I or ARB in AKI remains uncertain. Theoretically, these drugs reduce intraglomerular pressure and glomerular filtration rate (GFR) and may worsen AKI severity by increasing serum creatinine level. In the setting of cardiac surgery, Benedetto and colleagues showed that preoperative ACE-I use until the day of on-pump coronary artery bypass grafting reduced the incidence of postoperative AKI [21]. However, Arora and colleagues reported preoperative use of ACE-I or ARB were independently associated with a higher risk of postoperative AKI [22]. Wang and colleagues examined the effect of ACE-I prescription on clinical outcomes in AKI by analyzing the RENAL study data. The use of ACE-I during the study was not common $(9.7 \%)$ and was not significantly associated with a reduction in mortality after adjusting for time-dependent covariates [23]. Further evaluation is required to optimize renin-angiotensin system blockade treatment in AKI.

Another important consideration in the setting of AKI requiring RRT is antibiotic use, as dose adjustment based on renal dysfunction and dialysis intensity is required. Fundamental aspects of pharmacokinetics including clearance $(\mathrm{CL})$ and volume of distribution $(\mathrm{Vd})$ are drastically changed in critically ill patients with AKI due to loss of renal clearance, volume expansion, and interventions such as vasopressors and RRT. As CRRTassociated variables, effluent flow (dialysate flow, ultrafiltration rate), membrane fouling, and filter clotting can influence extracorporeal CL during CRRT. So far, data on antibiotic pharmacokinetics during CRRT are limited [24]. Roberts and colleagues studied 24 patients in the RENAL study to assess the effect of CRRT on extracorporeal and systemic antibiotic CL and Vd. They showed that there was great variability in multiple antibiotic pharmacokinetics, with greater variation observed in systemic CL than in Vd. These changes were not affected significantly by CRRT dose, suggesting the need for individual therapeutic drug monitoring regardless of CRRT dose [25].

\section{Nutritional support in AKI}

Achieving an adequate daily calorie intake (DCI) is considered beneficial in critically ill patients, especially in those complicated with AKI [26]. In an RCT that compared energy provision of 30 and $40 \mathrm{kcal} / \mathrm{kg} /$ day for AKI patients, the higher energy prescription did not induce a more positive nitrogen balance but was associated with a higher incidence of hyperglycemia and hypertriglyceridemia and a more positive fluid balance [27]. The KDIGO and the European Society for Clinical Nutrition and Metabolism (ESPEN) recommend achieving a total energy intake of $20-30 \mathrm{kcal} / \mathrm{kg} /$ day in patients with any stage of AKI [28]. Conversely, caloric restriction may be beneficial for critically ill patients with respiratory failure because of low $\mathrm{CO} 2$ production. However, two RCTs involving patients with acute lung injury or acute respiratory failure evaluated minimal or trophic enteral feeding (15-25\% of estimated caloric requirements) with no protein supplementation for up to 6 days and 
demonstrated that their outcomes were similar to those with standard enteral feeding $[29,30]$. A systematic review that evaluated eight RCTs concluded that there was insufficient evidence to support the effectiveness of nutritional support for AKI [31]. Especially in severe AKI requiring CRRT, there is very limited data on current practices or on the association of energy intake with the outcomes.

Bellomo and colleagues described calorie administration in patients enrolled in the RENAL study and evaluated the association of DCI with clinical outcomes. In the RENAL study, mean DCI appeared to be low; the mean DCI during treatment in the ICU was low at only $10.9 \pm 9 \mathrm{kcal} / \mathrm{kg} /$ day for non-survivors and $11 \pm 9 \mathrm{kcal} / \mathrm{kg} /$ day for survivors. Within the limits of such low caloric intake, greater DCI was not associated with improved clinical outcomes [32]. Higher level evidence is needed to better define the optimal DCI target in AKI patients.

Another issue regarding nutrition in AKI patients is the amount of protein intake. Delivering an adequate daily protein intake (DPI) is considered beneficial in critically ill patients in general and in patients with AKI specifically. The American Society for Parenteral and Enteral Nutrition (ASPEN) Guidelines recommend administering at least $1.0 \mathrm{~g} / \mathrm{kg} /$ day to patients with AKI requiring RRT with a maximum of $1.7-2.5 \mathrm{~g} / \mathrm{kg} /$ day [33]. Two prospective trials suggested a protein intake of $2.5 \mathrm{~g} / \mathrm{kg} /$ day was necessary to achieve positive nitrogen balance in patients with AKI requiring RRT [34, 35]. However, no outcome data are currently available concerning the clinical efficacy and safety of such high protein intake. In addition, most studies on protein intake in AKI conducted so far were small, single-center trials and evaluated only the nitrogen balance.

Bellomo and colleagues conducted a secondary analysis of the RENAL study findings focusing on the relationship between DPI and clinical outcomes. Patients in the RENAL study received a low DPI $(0.5 \mathrm{~g} / \mathrm{kg} /$ day $)$, markedly below current recommendations. However, a low DPI was not independently associated with a decreased risk of death at 90 days or an increase in mechanical ventilation, RRT, ICU, or hospital-free days [36]. Thus, as with DCI, data is not clear on the optimal DPI target in AKI patients. Further RCTs are needed to determine the optimal DCI and DPI targets according to the stage of AKI and RRT requirement.

\section{Long-term outcomes in AKI: renal recovery and quality of life}

The long-term outcomes and renal recovery of AKI are important issues; however, they are not as wellcharacterized as short-term prognoses. Despite significant progress in the epidemiology of AKI, forecasting long-term outcomes and renal recovery in each AKI patient continues to be a challenge. Three RCTs comparing the efficacy of CRRT versus intermittent hemodialysis found that Acute Physiology, Age, Chronic Health
Evaluation (APACHE) III score of $>100$ [37], low urine output, decrease in MAP after initiation of dialysis [38], and pre-existing renal impairment [39] were associated with poor renal recovery. Uchino and colleagues reported that baseline creatinine and urine output values at the time of RRT discontinuation were the strongest predictors of renal recovery based on the post hoc analysis of the Beginning and Ending Supportive Therapy for the Kidney (BEST Kidney) study [40], a large international epidemiological survey of acute renal failure in ICU patients [3].

Srisawat and colleagues conducted an ancillary study to the VA/NIH ATN study to determine whether biomarkers could aid in clinical risk prediction for recovery after AKI. They showed that decreased urinary neutrophil gelatinase-associated lipocalin (uNGAL) and urinary hepatocyte growth factor (uHGF) within the first 14 days after starting RRT were associated with greater odds of renal recovery. The best predictive model combined relative changes in biomarkers with clinical variables and had an AUC-ROC of 0.94 [41]. In addition to conventional clinical parameters, more accurate methods to predict renal recovery including the development and utilization of new AKI biomarkers are warranted to minimize the clinical uncertainty and complexity of medical decisionmaking during AKI treatment.

Health-related quality of life (HRQOL) after AKI is an area of great importance to patients. Noble and colleagues showed that quality of life (QOL) scores assessed by the Short Form-36 were significantly lower for overall physical health as well as for seven of the eight domains in AKI survivors than in general population [42]. Johansen and colleagues examined whether study treatment assignment (intensity of dialysis) and ongoing dialysis dependence at 60 days were potential determinants of HRQOL in the VA/NIH ATN study cohort. Health utility index score was low $(0.40 \pm 0.37)$ in this AKI survivor cohort, and the intensity of dialysis did not affect subsequent health utility whereas the length of hospital and ICU stay did [43]. Using the VA/NIH ATN study cohort, Joyce and colleagues conducted another study revealing that HRQOL measured by Health Utilities Index Mark 3 (HUI3) was an independent predictor of mortality among survivors of AKI after adjusting for clinical risk variables [44].

Wang and colleagues conducted an extension study within the RENAL study cohort by following up AKI survivors to evaluate the impact of AKI on long-term HRQOL (3.5 years after the RENAL study randomization). Unadjusted analyses showed that AKI patients had lower physical component scores (PCS; mean score, 40.0 vs. 49.8, $P<0.0001)$ and lower mental component scores (MCS; mean score, 49.8 vs. $53.9, P<0.0001$ ) than the general population. Advanced age, reduced renal function, 
and albuminuria were all strongly associated with lower PCS values [45]. The HRQOL may provide additional information to identify patients at high risk of mortality after surviving AKI.

\section{Perspectives}

Recent clinical guidelines consist of a list of clinical questions and answers. Strong evidence supported by numerous RCTs and high-quality meta-analysis studies are necessary to confirm the recommendations in the guidelines. However, economic, human resources, and ethical limitations hamper ideal RCTs designed to answer all clinical questions. Alternatively, clinically useful information can be retrieved from additional subanalyses or ancillary studies that use data from existing RCTs. Although the strength of evidence derived from the subanalysis studies described in this review was not sufficient compared with the two original RCTs (VA/NIH ATN and RENAL), the reported information by these subanalyses provide meaningful insights that can be applied to the clinical practice. It should be noted that the two RCTs have comprehensive and well-organized databases with large sample sizes.

\section{Conclusions}

This review summarizes additional findings related to RRT in AKI patients derived from the two landmark RCTs, the $\mathrm{VA} / \mathrm{NIH}$ ATN and the RENAL studies. Although these two RCTs demonstrated no beneficial effect with higher intensity RRT, additional useful information from subanalyses of these RCTs can be obtained.

\section{Ethics approval and consent to participate Not applicable.}

\section{Consent for publication}

Not applicable.

\section{Abbreviations}

ACE-l: angiotensin-converting enzyme inhibitor; AKl: acute kidney injury; APACHE: Acute Physiology, Age, Chronic Health Evaluation; ARB: angiotensin receptor blocker; ASPEN: American Society for Parenteral and Enteral Nutrition; ATN: Acute Renal Failure Trial Network; AUC-ROC: area under the curve receiver-operating characteristic; BEST Kidney: The Beginning and Ending Supportive Therapy for the Kidney; BUN: blood urea nitrogen; CCF: Cleveland Clinic Foundation; Cl: confidence interval; CL: clearance; CRRT: continuous renal replacement therapy; DCl: delivery of caloric intake; DPI: daily protein intake; ESPEN: European Society for Clinical Nutrition and Metabolism; GFR: glomerular filtration rate; HRQOL: health-related quality of life; HUI3: Health Utilities Index Mark 3; ICU: intensive care unit; IHD: intermittent hemodialysis; KDIGO: Kidney Disease: Improving Global Outcome; MAP: mean arterial pressure; MCS: mental component scores; OR: odds ratio; PCS: physical component scores; PICARD: Program to Improve Care in Acute Renal Disease; RCT: randomized controlled trial; RENAL: Randomized Evaluation of Normal versus Augmented Level; RIFLEI: Risk, Injury, Failure, Loss, End-stage kidney disease (injury); RR: relative risk; RRT: renal replacement therapy; SLED: sustained low efficiency dialysis; UHGF: urinary hepatocyte growth factor; UNGAL: urinary neutrophil gelatinase-associated lipocalin; VA/NIH: Veterans Affairs/National Institutes of Health; Vd: volume of distribution.
}

\section{Competing interests}

The authors declare that they have no competing interests.

\section{Authors' contributions}

TY and KD wrote this review. YK, RM, YM, KY, EN, MN, and NY participated in the editing of this article. All authors read and approved the final manuscript.

\section{Acknowledgements}

This study is partly supported by The University of Tokyo Clinical Research Training Program.

\section{Funding}

There is no funding to be disclosed.

\section{Author details}

${ }^{1}$ Department of Nephrology and Endocrinology, The University of Tokyo, Tokyo, Japan. ${ }^{2}$ Department of Emergency and Critical Care Medicine, The University of Tokyo, 7-3-1 HongoBunkyo, Tokyo 113-8655, Japan.

Received: 12 January 2016 Accepted: 9 February 2016

Published online: 20 April 2016

\section{References}

1. Bouchard J, Acharya A, Cerda J, Maccariello ER, Madarasu RC, Tolwani AJ, et al. A prospective international multicenter study of AKI in the intensive care unit. Clin J Am Soc Nephrol. 2015;10(8):1324-31. doi:10.2215/CJN.04360514.

2. Hoste EA, Clermont G, Kersten A, Venkataraman R, Angus DC, De Bacquer D, et al. RIFLE criteria for acute kidney injury are associated with hospital mortality in critically ill patients: a cohort analysis. Crit Care. 2006;10(3):R73. doi:10.1186/cc4915.

3. Uchino S, Kellum JA, Bellomo R, Doig GS, Morimatsu H, Morgera S, et al. Acute renal failure in critically ill patients: a multinational, multicenter study. JAMA. 2005;294(7):813-8. doi:10.1001/jama.294.7.813.

4. Hoste EA, Schurgers M. Epidemiology of acute kidney injury: how big is the problem? Crit Care Med. 2008;36(4 Suppl):S146-51. doi:10.1097/CCM. Ob013e318168c590.

5. VA/NIH Acute Renal Failure Trial Network, Palevsky PM, Zhang JH, O'Connor TZ, Chertow GM, Crowley ST, et al. Intensity of renal support in critically ill patients with acute kidney injury. N Engl J Med. 2008;359(1):7-20. doi:10. 1056/NEJMoa0802639.

6. Replacement Therapy Study Investigators RENAL, Bellomo R, Cass A, Cole L, Finfer S, Gallagher M, et al. Intensity of continuous renal-replacement therapy in critically ill patients. N Engl J Med. 2009:361(17):1627-38. doi:10. 1056/NEJMoa0902413.

7. Kidney Disease: Improving Global Outcomes (KDIGO) Acute Kidney Injury Work Group. KDIGO Clinical Practice Guideline for Acute Kidney Injury. Section 5: dialysis interventions for treatment of AKI. Kidney Int Suppl. 2012; 2(1):89-115. doi:10.1038/kisup.2011.35.

8. Bellomo R, Lipcsey M, Calzavacca P, Haase M, Haase-Fielitz A, Licari E, et al. Early acid-base and blood pressure effects of continuous renal replacement therapy intensity in patients with metabolic acidosis. Intensive Care Med. 2013;39(3):429-36. doi:10.1007/s00134-012-2800-0.

9. Overberger P, Pesacreta M, Palevsky PM, VA/NIH Acute Renal Failure Trial Network. Management of renal replacement therapy in acute kidney injury: a survey of practitioner prescribing practices. Clin J Am Soc Nephrol. 2007; 2(4):623-30. doi:10.2215/CJN.00780207.

10. Claure-Del Granado R, Macedo E, Chertow GM, Soroko S, Himmelfarb J, Ikizler TA, et al. Effluent volume in continuous renal replacement therapy overestimates the delivered dose of dialysis. Clin J Am Soc Nephrol. 2011; 6(3):467-75. doi:10.2215/CJN.02500310.

11. Kellum JA, Mehta RL, Levin A, Molitoris BA, Warnock DG, Shah SV, et al. Development of a clinical research agenda for acute kidney injury using an international, interdisciplinary, three-step modified Delphi process. Clin J Am Soc Nephrol. 2008;3(3):887-94. doi:10.2215/CJN.04891107.

12. Liu KD, Himmelfarb J, Paganini E, Ikizler TA, Soroko SH, Mehta RL, et al. Timing of initiation of dialysis in critically ill patients with acute kidney injury. Clin J Am Soc Nephrol. 2006;1(5):915-9. doi:10.2215/CJN.01430406.

13. Bagshaw SM, Uchino S, Bellomo R, Morimatsu H, Morgera S, Schetz M, et al. Timing of renal replacement therapy and clinical outcomes in critically ill patients with severe acute kidney injury. J Crit Care. 2009;24(1):129-40. doi:10.1016/j.jcrc.2007.12.017. 
14. Seabra VF, Balk EM, Liangos O, Sosa MA, Cendoroglo M, Jaber BL. Timing of renal replacement therapy initiation in acute renal failure: a meta-analysis. Am J Kidney Dis. 2008;52(2):272-84. doi:10.1053/j.jjkd.2008.02.371.

15. Bouman CS, Oudemans-Van Straaten HM, Tijssen JG, Zandstra DF, Kesecioglu J. Effects of early high-volume continuous venovenous hemofiltration on survival and recovery of renal function in intensive care patients with acute renal failure: a prospective, randomized trial. Crit Care Med. 2002;30(10):2205-11. doi:10.1097/01.CCM.0000030444.21921.EF.

16. Jun M, Bellomo R, Cass A, Gallagher M, Lo S, Lee J, et al. Timing of renal replacement therapy and patient outcomes in the randomized evaluation of normal versus augmented level of replacement therapy study. Crit Care Med. 2014;42(8):1756-65. doi:10.1097/CCM.0000000000000343.

17. Uchino S, Bellomo R, Morimatsu H, Morgera S, Schetz M, Tan I, et al. External validation of severity scoring systems for acute renal failure using a multinational database. Crit Care Med. 2005;33(9):1961-7. doi:10.1097/01.ccm.0000172279.66229.07.

18. Chertow GM, Soroko SH, Paganini EP, Cho KC, Himmelfarb J, Ikizler TA, et al. Mortality after acute renal failure: models for prognostic stratification and risk adjustment. Kidney Int. 2006;70(6):1120-6. doi:10.1038/sj.ki.5001579.

19. Halstenberg WK, Goormastic M, Paganini EP. Validity of four models for predicting outcome in critically ill acute renal failure patients. Clin Nephrol. 1997:47(2):81-6

20. Demirjian S, Chertow GM, Zhang JH, O'Connor TZ, Vitale J, Paganini EP, et al. Model to predict mortality in critically ill adults with acute kidney injury. Clin J Am Soc Nephrol. 2011;6(9):2114-20. doi:10.2215/CJN.02900311.

21. Benedetto U, Sciarretta S, Roscitano A, Fiorani B, Refice S, Angeloni E, et al. Preoperative angiotensin-converting enzyme inhibitors and acute kidney injury after coronary artery bypass grafting. Ann Thorac Surg. 2008;86(4): 1160-5. doi:10.1016/j.athoracsur.2008.06.018.

22. Arora P, Rajagopalam S, Ranjan R, Kolli H, Singh M, Venuto R, et al. Preoperative use of angiotensin-converting enzyme inhibitors/angiotensin receptor blockers is associated with increased risk for acute kidney injury after cardiovascular surgery. Clin J Am Soc Nephrol. 2008;3(5):1266-73. doi:10.2215/cjn.05271107.

23. Wang AY, Bellomo R, Ninomiya T, Lo S, Cass A, Jardine M, et al. Angiotensin-converting enzyme inhibitor usage and acute kidney injury: a secondary analysis of RENAL study outcomes. Nephrology. 2014;19(10):617-22. doi:10.1111/nep.12284.

24. Li AM, Gomersall CD, Choi G, Tian Q, Joynt GM, Lipman J. A systematic review of antibiotic dosing regimens for septic patients receiving continuous renal replacement therapy: do current studies supply sufficient data? J Antimicrob Chemother. 2009;64(5):929-37. doi:10.1093/jac/dkp302.

25. Roberts DM, Liu X, Roberts JA, Nair P, Cole L, Roberts MS, et al. A multicenter study on the effect of continuous hemodiafiltration intensity on antibiotic pharmacokinetics. Crit Care. 2015;19(1):84. doi:10.1186/s13054-015-0818-8.

26. Brown RO, Compher C. A.S.P.E.N. clinical guidelines: nutrition support in adult acute and chronic renal failure. JPEN J Parenter Enteral Nutr. 2010; 34(4):366-77. doi:10.1177/0148607110374577.

27. Fiaccadori E, Maggiore U, Rotelli C, Giacosa R, Picetti E, Parenti E, et al. Effects of different energy intakes on nitrogen balance in patients with acute renal failure: a pilot study. Nephrol Dial Transplant. 2005;20(9):1976-80. doi:10.1093/ndt/gfh956.

28. Cano N, Fiaccadori E, Tesinsky P, Toigo G, Druml W, Dgem, et al. ESPEN guidelines on enteral nutrition: adult renal failure. Clin Nutr. 2006;25(2):295-310. doi:10.1016/j.lnu.2006.01.023

29. Rice TW, Mogan S, Hays MA, Bernard GR, Jensen GL, Wheeler AP. Randomized trial of initial trophic versus full-energy enteral nutrition in mechanically ventilated patients with acute respiratory failure. Crit Care Med. 2011;39(5):967-74. doi:10.1097/CCM.0b013e31820a905a.

30. National Heart L, Blood Institute Acute Respiratory Distress Syndrome Clinical Trials N, Rice TW, Wheeler AP, Thompson BT, Steingrub J, et al. Initial trophic vs full enteral feeding in patients with acute lung injury: the EDEN randomized trial. JAMA. 2012;307(8):795-803. doi:10.1001/jama.2012.137.

31. Li Y, Tang $X$, Zhang J, Wu T. Nutritional support for acute kidney injury. Cochrane Database Syst Rev. 2012;8:Cd005426. doi:10.1002/14651858. CD005426.pub3.

32. Bellomo R, Cass A, Cole L, Finfer S, Gallagher M, Lee J, et al. Calorie intake and patient outcomes in severe acute kidney injury: findings from The Randomized Evaluation of Normal vs. Augmented Level of Replacement Therapy (RENAL) study trial. Crit Care. 2014;18(2):R45. doi:10.1186/cc13767.
33. McClave SA, Martindale RG, Vanek W, McCarthy M, Roberts P, Taylor B, et al. Guidelines for the provision and assessment of nutrition support therapy in the adult critically ill patient: Society of Critical Care Medicine (SCCM) and American Society for Parenteral and Enteral Nutrition (A.S.P.E.N.). JPEN Journal Parenter Enteral Nutr. 2009;33(3):277-316. doi:10.1177/0148607109335234.

34. Bellomo R, Tan HK, Bhonagiri S, Gopal I, Seacombe J, Daskalakis M, et al. High protein intake during continuous hemodiafiltration: impact on amino acids and nitrogen balance. Int J Artif Organs. 2002;25(4):261-8.

35. Scheinkestel CD, Adams F, Mahony L, Bailey M, Davies AR, Nyulasi I, et al. Impact of increasing parenteral protein loads on amino acid levels and balance in critically ill anuric patients on continuous renal replacement therapy. Nutrition. 2003;19(9):733-40. doi:10.1016/s0899-9007(03)00107-2.

36. Bellomo R, Cass A, Cole L, Finfer S, Gallagher M, Lee J, et al. Daily protein intake and patient outcomes in severe acute kidney injury: findings of the randomized evaluation of normal versus augmented level of replacement therapy (RENAL) trial. Blood Purif. 2014;37(4):325-34. doi:10.1159/000363175.

37. Mehta RL, McDonald B, Gabbai FB, Pahl M, Pascual MT, Farkas A, et al. A randomized clinical trial of continuous versus intermittent dialysis for acute renal failure. Kidney Int. 2001;60(3):1154-63. doi:10.1046/j.1523-1755.2001. 0600031154.x

38. Augustine JJ, Sandy D, Seifert TH, Paganini EP. A randomized controlled trial comparing intermittent with continuous dialysis in patients with ARF. Am J Kidney Dis. 2004;44(6):1000-7. doi:10.1053/.jajkd.2004.08.022.

39. Uehlinger DE, Jakob SM, Ferrari P, Eichelberger M, Huynh-Do U, Marti HP, et al. Comparison of continuous and intermittent renal replacement therapy for acute renal failure. Nephrol Dial Transplant. 2005;20(8):1630-7. doi:10.1093/ndt/gfh880

40. Uchino S, Bellomo R, Morimatsu H, Morgera S, Schetz M, Tan I, et al. Discontinuation of continuous renal replacement therapy: a post hoc analysis of a prospective multicenter observational study. Crit Care Med. 2009:37(9):2576-82. doi:10.1097/CCM.0b013e3181a38241.

41. Srisawat N, Wen X, Lee M, Kong L, Elder M, Carter M, et al. Urinary biomarkers and renal recovery in critically ill patients with renal support. Clin J Am Soc Nephrol. 2011;6(8):1815-23. doi:10.2215/CJN.11261210.

42. Noble JS, Simpson K, Allison MEM. Long-term quality of life and hospital mortality in patients treated with intermittent or continuous hemodialysis for acute renal and respiratory failure. Ren Fail. 2006;28(4):323-30. doi:10.1080/08860220600591487.

43. Johansen KL, Smith MW, Unruh ML, Siroka AM, O'Connor TZ, Palevsky PM. Predictors of health utility among 60-day survivors of acute kidney injury in the Veterans Affairs/National Institutes of Health Acute Renal Failure Trial Network Study. Clin J Am Soc Nephrol. 2010;5(8):1366-72. doi:10.2215/cjn.02570310

44. Joyce VR, Smith MW, Johansen KL, Unruh ML, Siroka AM, O'Connor TZ, et al. Health-related quality of life as a predictor of mortality among survivors of AKI. Clin J Am Soc Nephrol. 2012;7(7):1063-70. doi:10.2215/CJN.00450112.

45. Wang AY, Bellomo R, Cass A, Finfer S, Gattas D, Myburgh J, et al. Healthrelated quality of life in survivors of acute kidney injury: the Prolonged Outcomes Study of the Randomized Evaluation of Normal versus Augmented Level Replacement Therapy study outcomes. Nephrology. 2015;20(7):492-8. doi:10.1111/nep.12488.

\section{Submit your next manuscript to BioMed Central and we will help you at every step:}

- We accept pre-submission inquiries

- Our selector tool helps you to find the most relevant journal

- We provide round the clock customer support

- Convenient online submission

- Thorough peer review

- Inclusion in PubMed and all major indexing services

- Maximum visibility for your research

Submit your manuscript at www.biomedcentral.com/submit 